\title{
SÉCULO XVII NA FRANÇA: LES BELLES INFIDELES, RACINE E O MODELO DOS CLÁSSICOS ANTIGOS
}

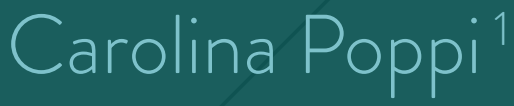

RESUMO: A história da tradução permite ao estudioso dessa área entrar em contato com diversos modelos adotados em diferentes momentos da história dessa prática. Em relação à história da tradução na França, um momento específico do século XVII chama a atenção dos estudiosos até nossos dias, o período conhecido como Les Belles Infidèles. Prática exercida sobretudo entre os anos 1625-1665 e auge de 1640 a 1650, segundo Zuber (1995, p.V), as traduções da "Idade da Eloquência" ainda suscitam preconceitos e interpretações equivocadas frente a uma prática moderna que segue princípios mais objetivos. Assim, este artigo, primeiramente, procurará caracterizar esse período, inserindo-o no quadro específico pelo qual passava a França naquele momento. Na sequência, a tradução praticada no período conhecido como Les Belles Infidèles será renomeada como uma "adaptação ou recriação a partir dos modelos antigos", o que será demonstrado de forma prática por meio de uma comparação entre uma tradução de Nicolas Perrot d'Ablancourt e de alguns trechos da peça Les Plaideurs de Jean Racine, datada de 1668, e a peça grega Les Guêpes de Aristófanes de 422 a.C.. Tal comparação possibitará, como conclusão, a afirmação de que a literatura clássica francesa é uma legítima herdeira da época das "traduções infiéis".

PALAVRAS-CHAVE: tradução, Les Belles Infidèles, Jean Racine, Les Plaideurs
1 Mestranda da área de Estudos Linguísticos, Literários e Tradutológicos em Francês, D L M / F F L C H / U S P. E-mail: capoppi@usp.br 
RESUMÉ : L'histoire de la traduction permet au chercheur de ce domaine de rentrer en contact avec les différents modèles adoptés dans plusieurs moments de l'histoire de cette pratique. En ce qui concerne l'histoire de la traduction en France, un moment particulier du XVIIe siècle attire l'attention des studieux jusqu'à nos jours, la période connue comme Les Belles Infidèles. Pratique développée surtout entre 1625-1665 dont l'apogée était les années 1640 à 1650 . Selon Zuber (1995: V), les traductions de « l'Age de l'éloquence " suscitent encore des préjugés et des malentendus au cadre d'une pratique moderne qui suit des principes plus objectifs. De cette façon, cet article, d'abord, essayera de caractériser cette période, la plaçant dans le contexte spécifique dans lequel la France traversait à ce moment. En outre, deuxièmement, la traduction exécutée pendant la période connue comme Les Belles infidèles sera ici renommée par « re-création ou adaptation du modèle des anciens ", ce qui sera démontré de façon pratique grâce à une comparaison d'une traduction de Nicolas Perrot d'Ablancourt de 1664 et quelques extraits de la pièce Les Plaideurs de Jean Racine, datée de 1668, et Les guêpes comédie grecque d'Aristophane de 422 av. J.-C. Une telle comparaison rendra, comme conclusion, l'affirmation selon laquelle la littérature classique française est une héritière légitime de l'époque des « traductions infidèles ».

MOTS-CLÉS : traduction, Les Belles Infidèles, Jean Racine, Les Plaideurs.

\footnotetext{
Por intuição ou por profissão, explicitamente ou não, o homem de letras clássico é sempre, de alguma forma, um tradutor (ZUBER, 1995: XIII)2.
}

\section{A literatura francesa dos séculos XVI e XVII: a tradução e o modelo dos clássicos antigos}

O período literário conhecido como Les Belles Infidèles, prática do século XVII (1625-1650), cujo apogeu se dá entre os anos 1640 e 1650 na França, é ainda objeto de muitas dúvidas e, principalmente, críticas. Os estudos da hoje chamada Tradutologia e a prática dessa "ciência" como disciplina intelectual e atividade pensante não podem direcionar depreciativamente o estudioso ou profissional da tradução em relação às
2 Par intuition ou par profession, explicitement ou non, l'homme de lettres classique est toujours plus ou moins un traducteur (ZUBER, 1995, p.XIII). 
práticas anteriores. Isso porque, ao longo da história e em diversos países, a tradução nunca se apresentou como uma prática de princípios únicos e estáticos, apesar das várias correntes similares desenvolvidas em diferentes períodos e locais. Muitas são as abordagens teóricas que se podem fazer de uma tradução e, em muitos períodos, diferentes práticas foram adotadas. É a partir desses parâmetros que o estudioso deve compreender o período em questão: sob um determinado ponto de vista histórico, localizado em um espaço e um tempo preestabelecidos; o espaço é a França do século XVII, o tempo, o chamado período das Belles Infidèles.

A tradução, prática considerada como arte e classificada como gênero literário nessa época, desde o final da Idade Média, por meio de movimentos como o Renascimento e o Humanismo europeus, desempenhou um importante papel na formação das línguas e literaturas nacionais de muitos países, entre eles, a França. Segundo Balliu (1995, p.09), o contato com obras em latim antes restritas aos cléricos e também o acesso a obras originais em grego, mesmo que esta língua fosse um limitador à época, ou seja, o modelo dos antigos, bem como o protestantismo do século XVI proporcionaram aos países europeus um rompimento com a ignorância disseminada na Idade das Trevas e, aos poucos, a construção da cultura e língua nacionais, resultando, na França do século XVII, no movimento conhecido como Les Belles Infidèles.

O principal papel da tradução de obras da Antiguidade Clássica grega e latina na Europa desde o final do século XIII, segundo Zuber (1995, p.21), era o mais nobre dos ofícios: o apetite pelo saber, necessidade trazida pelo movimento humanista de colocar o homem e o conhecimento no centro das preocupações humanas, e o fim das restrições de acesso aos modelos originais clássicos. A ânsia por traduções para o francês de obras orginais em latim, porém, propiciaram no período correspondente aos anos 1477 a 1527 (ZUBER, 1995, p.22) um excesso de traduções latinizadas que não seguiam critérios nem formas da língua de chegada, o francês. Foi assim que, em 1540, Etienne Dolet publica sua Manière de bien traduire d'une langue en autre ${ }^{3}$ na tentativa de estabelecer regras para essa atividade, dentre as quais, a defesa de uma tradução que tivesse como foco o receptor e a língua materna do público-alvo (ideias trazidas sobretudo pelo movimento protestantista do século XVI, do qual Dolet era adepto, o que lhe custou a acusação de blasfêmia, sedição e exposição de livros proibidos, bem como sua condenação a ser queimado com seus livros na praça Maubert, em Paris, lugar de suplícios dos heréticos $(2004$, p.15) e não uma mera imitação das estruturas do latim, estranhas aos receptores, e uma latinização do francês desacompanhada de uma atividade interpretativa, como se fazia em boa parte das obras traduzidas. Ou seja, Dolet criticava a prática da tradução com foco no texto de partida. A questão é apresentada por Balliu (1995,
3 Segundo Dolet em La manière de traduire d'une langue en autre, são necessários cinco aspectos para traduzir bem de uma língua a outra: (i)o tradutor deve entender perfeitamente o sentido e a matéria do autor a ser traduzido sob pena de não traduzir com segurança $\mathrm{e}$ fidelidade; (ii) o conhecimento perfeito por parte do tradutor da língua do autor que ele traduz e da língua na qual se propõe a traduzir; (iii) a desnecessidade de verter, na tradução, palavra por palavra, o que demonstraria pobreza e falta de engenho por parte do tradutor; (iv) evitar, sobretudo em línguas não sistematizadas como a italiana, a francesa, a espanhola, a alemã, a inglesa e outras vulgares, usurpar palavras muito próximas do latim e pouco usadas no passado; o tradutor deve contentar-se com as comuns, "sem inventar neciamente certas expressões por um capricho censurável"; e, por fim, (v) a observância da harmonia do discurso, isto é, "um enlace e união das palavras com tal suavidade, que não apenas a alma se satisfaça, mas também os ouvidos se sintam completamente fascinados $\mathrm{e}$ não se cansem jamais com tal harmonia da linguagem". Para Dolet, a última obervância é tão importante que, sem ela, "qualquer composição fica pesada e pouco agradável". (DOLET, E. "A maneira de bem traduzir de uma língua para outra". In BORGES DE FAVERI,C; TORRES, MarieHelène Catherine (Org.). «La manière de bien traduire d'une langue en autre». Trad. Pierre Guisan. In Clássicos da Teoria da Tradução- Antologia bilíngue/ francês-português, Volume II, 2004, p.15-21) 
p.11) como primordial na formação da língua nacional na França, haja vista a escassez naquele momento de um amplo vocabulário e a necessidade de uma construção autônoma da língua de chegada das traduções, que contivesse suas especificidades.

O prestígio dessa arte, porém, que debutava traços de autonomia na figura de Etienne Dolet não teve tempo de ser consolidado, uma vez que a atividade da tradução novamente começou a ser questionada com a publicação em 1555 de l'Art poetique, de Hugues Salel, o qual demonstra pouco entusiasmo pela prática da forma como era exercida, além de, na mesma época, ser considerada pelos poetas da Pléiade ${ }^{4}$ como uma atividade literária menor, por não propiciar o desenvolvimento da língua nacional (ZUBER, 1995, p.23). O gênero da prosa, em razão da escassez de vocabulário do idioma (o francês ainda era uma língua não sistematizada à época), não tinha tanto prestígio como a poesia ou a oratória, gêneros já consolidados como nobres. Para Du Bellay, um dos nomes da Pléiade, a questão era muito mais ideológica que estética: não se podia traduzir a eloquência de uma língua para a outra, além disso, a tradução de poesia era perniciosa dado que profanaria a arte dos antigos. A defesa da criação na própria língua era o objetivo de Du Bellay, razão pela qual a Pléiade incentivava os poetas e oradores em detrimento dos tradutores (BALLIU, 1995, p.12) $)^{5}$. Com essa reviravolta, as práticas tradutórias se rarefazem, havendo um rebaixamento do gênero desde os anos 1560 e, praticamente inexistindo por volta dos anos 1610. Du Bellay tem papel fundamental nessa questão: para ele e para o seu grupo, devia-se privilegiar, na tradução, a estética da língua nacional, e a tradução como mera imitação das formas dos clássicos não traria vantagens a esse propósito. Essa é, portanto, a base da construção literária da "Idade de Ouro da literatura francesa" e também do movimento posteriormente conhecido como Les Belles Infidèles: o culto ao modelo dos antigos, premissa que não se restringia apenas ao gênero da tradução e que tinha como propósito a ampliação do conhecimento humano, segundo uma estética autônoma da língua francesa (BALLIU, 1995, p.12).

É, porém, na figura de Jacob Amyot (1513-1593), um dos mais célebres tradutores franceses, inclusive de obras gregas, o que era raro à época, e um dos únicos literatos a não aderir à tendência da prosa poética, que a tradução de uma prosa natural é retomada como atividade de prestígio na França do século XVI, apesar das dificuldades impostas pelas instituições e grupos de críticos, a exemplo da Pléiade. Assim como Dolet, segundo Balliu (1995, p.13) Amyot defende o enriquecimento da língua francesa, a criação de palavras e frases que sejam naturalmente francesas, o estabelecimento de uma eloquência e de estilo próprios também na prosa. Essas ideias representarão uma mudança de rumo no papel que a tradução
4 Du Bellay, segundo Zuber (1995, p.23), afirma que o ofício dos tradutores é secundário se comparado, por exemplo, aos dos poetas e oradores. Já Etinne Pasquier, em 1594, segundo o mesmo autor (ZUBER, p.24) afirma que a tradução é um "labeur misérable, ingrat et esclave".

5 Em 1549, Joackim du Bellay (1522-1560) publica um pequeno livro intitulado La Deffence et illustration de la langue françoyse. No capítulo V, estabelece que há cinco partes na arte do bem falar: a invenção, a elocução, a disposição, a memória e a pronúncia. Dispõe-se a estabelecer regras para as duas primeiras, a invenção a elocução, pois as outras três têm caráter pessoal e são desenvolyidas segundo a natureza de cada indivíduo. Em relação à invenção, dado que para o autor a boa oratória deve pressupor a compreensão perfeita das ciências, o que deve ser feito por meio de estudo dos gregos e latinos, os tradutores podem e muito contribuir para ajudar aqueles que não possuem a compreensão das línguas antigas. Já no que diz respeito à elocução, segundo Du Bellay, nunca se poderá, para ser um bom orador, aprender a eloquência de uma língua por meio da tradução, porque é "impossível reproduzir com a mesma elegância que o 
vinha tendo na época, ou seja, um papel de mera imitação estética dos antigos, com pouca autonomia de criação na sintaxe e semântica da língua de chegada, bem como representa mais uma vez o fundamento da "Idade de Ouro da literatura francesa": a construção de uma língua autônoma que buscasse suas próprias características e sua própria estética na tradução também da prosa, apesar da inspiração no modelo dos antigos.

Assim, pode-se afirmar que a tradução, arte considerada como gênero literário na França do século XVI, mesmo em crise, estava em busca da consagração de novos talentos, os quais conseguem se reafirmar no século XVII, apesar dos obstáculos, como prosadores de um estilo bastante pessoal e de um campo de ação privilegiado, o qual atingirá prestígio, finalmente, nos anos 1625 a 1665 com tradutores como Bachet de Méziriac (1581-1638), Guez de Balzac (1597-1654) e Nicolas Perrot d'Ablancourt (1606-1664). As diversas formas de se encarar a prática da tradução nos séculos mencionados, mesmo que desencontradas e até opostas em alguns momentos, partem de um mesmo ponto e seguem para um mesmo objetivo: adaptar em estética própria as obras em língua latina e grega aos gostos e práticas do público de sua época, sem perder jamais a referência no modelo dos antigos.

\section{Les Belles Infidèles e Nicolas Perrot d'Ablancourt}

A língua francesa clássica como a conhecemos hoje foi sendo estabelecida entre os anos de 1600 a 1660 (BALLIU, 1995, p.16), período em que havia uma intensa instabilidade linguística na França. Durante o século XVII, em decorrência do estabelecimento, por diversos eruditos bem como pela Academia francesa, criada em 1634, de uma língua de referência e de prestígio, imposta pelas altas esferas da sociedade, houve também reflexos dessas regras linguísticas de poder na prática tradutória.

A formação do esteticismo exacerbado da língua francesa chamado "bom gosto", cujo processo instável foi sucintamente demonstrado no capítulo anterior, determinará, durante todo o século XVII, o estilo da língua de chegada em tradução (BALLIU, 1995, p.17). A prática da referência aos antigos é imprescindível, mas como não se é possível imitá-los de perto, uma vez que o período histórico é outro, os literatos dessa época, incluindo os tradutores, o fazem por meio de uma "imitação à distância" (BALLIU, 1995, p.17), baseada em uma adequação entre estilo e época. E esse foi o meio pelo qual os tradutores e poetas do século XVII e XVIII francês construíram sua literatura clássica: adaptando e recriando os antigos ao gosto do público, segundo as normas do "bom gosto" dos eruditos e, a partir de 1634, das regras de "eloquência" da Academia francesa. autor usou." No capítulo VI, Du Bellay critica os tradutores que ousam traduzir poesia pois, segundo suas palavras, estariam profanando "les sacrées reliques de l'antiquité!". A tradução de poesia, assim, seria uma tarefa trabalhosa, pouco proveitosa, inútil e até perniciosa para o desenvolvimento da língua, e os poetas que ousam fazê-lo, ganham com toda justiça mais aborrecimento do que glória (DU BELLAY, J. "Defesa e ilustração da língua francesa". In: BORGES DE FAVERI,C; TORRES, MARIE-HELENE C. (Org.). «Défense et illustration de la langue française». Trad. Philipe Humblé In Clássicos da Teoria da Tradução- Antologia bilíngue/francês-português, Volume II, 2004, p.24-31). 
Assim, é possível falar, durante o período conhecido como Les Belles Infidèles, em traduções que seguem uma fidelidade estilística dinâmica e uma equivalência de efeitos (BALLIU, 1995, p.17): ao contrário dos conceitos como hoje são entendidos, os escritores franceses dessa época praticavam a tradução segundo as regras modernas estilísticas e de eloquência impostas pelas instituições de bom gosto a partir de modelos antigos, dos quais se mantinham os efeitos.

O nome Belles Infidèles, por sua vez, é uma metáfora empregada no século XVII por Giles Ménage (1613-1692) ao referir-se às traduções de Nicolas Perrot D'ABLANCOURT (1606-1664) um dos representantes mais conhecidos desse período:

Assim que a versão de Lucien de M. d'Ablancourt foi publicada, muitas pessoas reclamaram que ela não era fiel. De minha parte, eu a chamei de "bela infiel" nome que dei na juventude a uma de suas amantes (BALLIU, 1995, p.15) ${ }^{6}$.

Nicolas Perrot d'Ablancourt era um profundo conhecedor das línguas grega e latina, e foi tradutor de Cícero, Tácito, Xenofonte, César, Luciano, entre outros clássicos antigos. Eram nos prefácios que antecediam suas traduções que esse tradutor explicitava seus métodos, deixando para a posteridade os próprios procedimentos do período aqui estudado. No prefácio intitulado Carta ao Senhor Conrart Conselheiro e Secretário do Rei, texto que figura na introdução da tradução de Tratados e Diálogos de Luciano (1664), obra pela qual suas traduções ficaram conhecidas como "belas infiéis", d'Ablancourt expõe seu método:

Tudo o que se pode dizer contra mim pode relacionar-se a dois pontos principais: à intenção e ao procedimento. Pois alguns dirão que não seria necessário traduzir esse autor e outros, que seria preciso traduzi-lo de outra forma (D’ABLANCOURT, 2004, p.51, grifo nosso).

Para apresentar seu método quanto à intenção, ele faz uma longa exposição a respeito do poeta Luciano: local de nascimento, costumes, profissão, formação, viagens, tempo de vida, religião etc, e à medida que descreve o poeta, também o julga:

De resto, a maneira como trata os assuntos mais importantes mostra que não era muito versado em filosofia e que dela aprendeu somente o que servia para sua profissão de retórico, que era a de falar contra ou a favor de qualquer assunto (D’ABLANCOURT, 2004, p.53).
6 «Lors que la version de Lucien de M. d'Ablancourt parut, bien des gens se plaignirent de ce qu'elle n'étoit pas fidèle. Pour moi je l'appelai la belle infidèle, qui étoit le nom que j'avois donné étant jeune à une de mes maîtresses» (BALLIU, 1995, p.15).
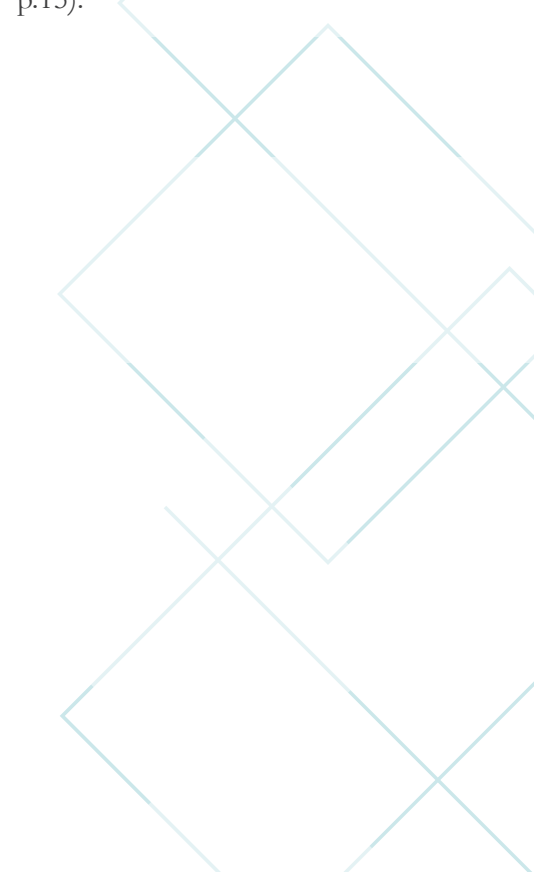
A intenção, por fim, é mostrar que a tradução de Luciano é justificável, já que muitas outras pessoas doutas a fizeram. Ninguém pode condená-lo por tê-la feito, uma vez que aquilo que em Luciano não é agradável, o que é grosseiro, foi suavizado por ele, tradutor, motivo pelo qual a leitura dessa obra traz tantas vantagens ao público (D’ABLANCOURT, 2004, p.55).

Quanto ao procedimento da tradução, D'Ablancourt (2004, p.55) o descreve da seguinte forma: (i)assume não ter feito uma tradução comum (traduction régulière); (ii)aponta questões de intraduzibilidade (propriedades dos termos gregos que não seriam entendidas fora do contexto); (iii)exclui as comparações do amor, pois trata-se do amor aos rapazes ("o que não era estranho aos costumes da Grécia e que horrorizam os nossos"); e (iv) exclui os versos que fazem referência a Homero, as velhas fábulas batidas, os provérbios, exemplos e comparações antiquados uma vez que seriam "agora" pedantes e trata-se de galanteria e não de erudição; e acrescenta

Assim como nos belos rostos há sempre algo que gostaríamos que não estivesse ali, do mesmo modo, nos melhores autores, há passagens que convêm retocar ou esclarecer, especialmente quando as coisas são feitas somente para agradar; pois então não se pode suportar o mínimo defeito, e se a delicadeza faltar nem que seja por pouco, em vez de agradar, aborrece (D’ABLANCOURT, 2004, p.55, grifo nosso).

D'Ablancourt explicita que sua tradução tem uma finalidade, a qual deve ser buscada. Para isso, diz não se apegar sempre às palavras ou aos pensamentos do autor, mas sim manter a finalidade, arranjando as coisas a "nosso gosto e a nosso modo":

As diversas épocas pedem não somente palavras, mas pensamentos diferentes; e os embaixadores têm o hábito de se vestirem à moda do país para onde são enviados, por medo de parecerem ridículos perante aqueles que se esforçam por agradar (D'ABLANCOURT, 2004, p.57).

Por fim, cita exemplos de antigos que fizeram exatamente o que faz, o que assume não ser exatamente uma tradução, como Terêncio nas comédias de Menandro, e Cícero em seus Ofícios. D’Ablancourt, assim, assume que em muitas passagens traduziu palavra por palavra (2004, p.57), mas que quanto ao sentido, considerou mais ou que seria preciso dizer ou o que se podia dizer (2004, p.57).

Pode-se, concluir, diante do prefácio apresentado, que d'Ablancourt resume o método do período conhecido como Les Belles Infidèles: a tradução 
é uma referência à literatura dos antigos (intenção), mas o procedimento é a forma da sua época, a adaptação ou recriação da linguagem segundo as regras da Academia francesa e das instituições do "bom gosto".

\section{Racine e o modelo da comédia Les Plaideurs}

Não é só na tradução, porém, que se encontram as regras impostas para a literatura do século XVII francês. Em outros gêneros literários como o teatro, a herança das práticas das Belles Infidèles também se impõe. Um dos representantes dessa prática no teatro é Racine.

Jean Baptiste Racine foi um dramaturgo, poeta e historiador francês, nascido em 22 de dezembro de 1639 em Ferté-Milon, Aisne, França e falecido em 21 de abril de 1699 em Paris. Órfão ainda muito jovem, ele foi acolhido em Port-Royal, tendo estudado na École des messieurs desse monastério jansenista, local onde adquiriu uma cultura clássica sólida e onde aprendeu grego com o famoso professor Dom Claude Lancelot, entrando em contato muito cedo com autores gregos como Aristófanes e romanos como Plauto e Terêncio. Inicialmente ligado a Molière e à sua trupe de Port-Royal com os quais produziu sua primeira peça em 1664, La Thebaïde, Racine se estabelece posteriormente com a trupe do Hôtel de Bourgogne, com a qual produz suas demais peças, incluindo sua única comédia de 1668, Les Plaideurs.

À época de Racine, literatos, poetas e tradutores se inspiravam no modelo dos antigos para (re)criarem suas obras. Assim, pode-se apontar, segundo os estudiosos de Racine, três modelos nos quais o autor se inspirou para compor a comédia Les Plaideurs: (i)o modelo da peça Les Guêpes, do dramaturgo grego Aristófanes; (ii)o modelo de tradição literária francesa de sátira ao mundo da justiça que remonta À la Farce de Maître Pathelin do século XV e observa-se em Rabelais com Tiers Livre de 1546 e Quart Livre de 155 e em Furétière com Roman Bourgeois de 1666 e; (iii)a terminologia jurídica e os modos das pessoas ligadas à prática da justiça do Ancien Régime.

A filiação de sua obra em um modelo antigo é o apoio principal do enredo. O modelo é a peça Les Guêpes, comédia de Aristófanes (447 a.C. - 385 a.C). O próprio Racine assume que compôs a peça a partir dos elementos da comédia grega; porém, deve-se ressaltar que Aristófanes apresentava dentre suas características uma veia satírica violenta, um cômico trivial e, muitas vezes, até escatológico (FORESTIER, 2006, p.12), o que poderia, caso a linguagem não fosse adaptada a seu tempo e ao gosto do público, quebrar com a ordem estabelecida do bom gosto. No prefácio da peça, Racine se defende em razão da escolha por Aristófanes: 
Mas então eu traduzi Aristófanes, e devemos nos lembrar que ele lidava com espectadores bastante difíceis. Os atenienses aparentemente sabiam o que era o sal ático, eles tinham muita certeza do que riam, e não riam à toa por qualquer besteira (RACINE, 2006, p.35)

Um elemento que chama a atenção na declaração de Racine é que a diferença entre inspiração em um modelo antigo e tradução de um modelo antigo, como se entendia no século XVII na França, não era tão distante quanto se pode supor atualmente, e as palavras de Racine não desmentem essa hipótese quando afirma « Je traduis Aristophane».

Aristófanes era, porém, um autor antigo de pouco prestígio na França do século XVII e Racine se vê obrigado a adequar a linguagem de acordo com as regras de polidez de sua época, e essa preocupação em explicar sua inspiração está também ressaltada no prefácio da peça:

Eu disse a eles [a alguns amigos meus] que apesar da espiritualidade desse autor, minha preferência não era tomá-lo [Aristófanes] por referência se quissesse compor uma comédia; além disso, a regularidade de Menandro e de Terêncio me parecia muito mais gloriosa e mesmo mais agradável de imitar que a liberdade de Plauto e de Aristófanes. Eles me responderam que não era uma comédia o que me pediam, mas ver se as bonitas palavras de Aristófanes teriam algum encanto na nossa língua (RACINE, 2006, p.33-34) ${ }^{8}$.

Essa escolha de Racine, que, segundo o estudioso Huet (1999, p.26), representava uma estratégia para criar autonomia perante Molière, autor com o qual mantinha uma disputa em razão da fidelidade extrema aos textos dos antigos, ressalta a instabilidade dos procedimentos seguidos no século XVII na França e apresenta a questão da filiação e imitação servil dos antigos como um processo de amadurecimento da própria literatura clássica francesa: usando como modelo Aristófanes, o autor afasta-se do dogma da verossimilhança e do ideal de fidelidade na execução da reprodução dos modos da época e mostra que o trabalho do Hôtel de Bourgogne não era somente comercial, acusação a qual vinham sofrendo seus trabalhos, ao mesmo tempo em que mantém as regras da Academia francesa em relação ao "bom gosto" da linguagem, reafirmando os conceitos da equivalência dinâmica e adaptação dos efeitos ao gosto do público.

Assim, diante da comparação entre o modelo de tradução utilizado na prática do período conhecido como Les Belles Infidèles e o modelo de inspiração utilizado pelos autores dos outros gêneros literários da mesma época, na figura de Racine, pode-se afirmar que a tradução não era a
7 « (...) Mais enfin je traduis Aristophane, et l'on doit se souvenir qu'il avait affaire à des Spectateurs assez difficiles. Les Athéniens savaient apparemment, ce que c'était que le sel Attique, et ils étaient bien sûrs quand ils avaient ri d'une chose, qu'ils n'avaient pas ri d'une sottise »RACINE, 2006, p.35).

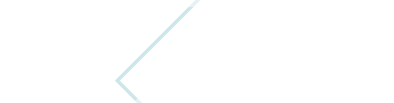

8 « Je leur dit [à quelques uns de mes amis] que quelque esprit que je trouvasse dans cet auteur, mon inclination ne me porterait pas à le prendre [Aristophane] pour modèle, si j'avais à faire une Comédie ; et que la régularité de Ménandre et de Térence me semblait bien plus glorieuse, et même plus agréable à imiter, que la liberté de Plaute et d'Aristophane. On me répondit que ce n'était pas une comédie qu'on me demandait, et qu'on voulait seulement voir si les bons mots d'Aristophane auraient quelque grâce dans notre langue »(RACINE, 2006, p.33-34). 
prática que hoje conhecemos, o que a faz adquirir um caráter totalmente específico e contextualizado, o caráter de adpatação e recriação a partir dos modelos dos antigos, ressaltando os conceitos de fidelidade estilística e equivalência de efeitos. Encarar a tradução do período das Belles Infidèles como uma prática que não alterará o texto de partida é um erro por parte do estudioso. Para se comprovar essa hipótese, apresentam-se dois trechos de "traduções". O primeiro é um trecho de uma tradução do período Les Belles Infidèles na figura de seu tradutor mais célebre, Nicolas Perrot d'Ablancourt, e o segundo é um trecho da comédia Les Plaideurs frente a sua fonte inspiradora, Les Guêpes de Aristófanes.

\begin{tabular}{|c|c|}
\hline $\begin{array}{l}\text { LUCIEN. Histoire véritable. In « } \\
\text { Romans grecs et latins ». Textes } \\
\text { présentés, traduits et annotés par } \\
\text { Pierre Grimal, Coll. La Pléiade, } \\
\text { Gallimard, Paris, } 1958 .^{9}\end{array}$ & $\begin{array}{l}\text { LUCIEN DE SAMOSATE. } \\
\text { Histoire véritable. Récit traduit } \\
\text { du grec ancien et présenté par } \\
\text { Perrot d'Ablancourt. Les belles } \\
\text { infidèle, Actes Sud, Arles, } 1988 . \\
\text { p. } 298 .^{10}\end{array}$ \\
\hline $\begin{array}{l}\text { (...) } \\
\text { J'ai vu encore une autre merveille } \\
\text { dans le palais royal : un très grand } \\
\text { miroir est disposé au-dessus d'un } \\
\text { puits, qui n'est pas fort profond. } \\
\text { Si quelqu'un descend dans ce } \\
\text { puits, il entend tout ce qui est dit } \\
\text { chez nous, sur la terre, et si l'on } \\
\text { regarde dans le miroir, on voit } \\
\text { toutes les cités, toutes les nations, } \\
\text { exactement comme si l'on était au } \\
\text { milieu d'elles. A cette occasion, je } \\
\text { vis moi-même ma famille, ainsi } \\
\text { que ma patrie toute entière, mais } \\
\text { me virent-ils eux-mêmes, cela } \\
\text { je ne puis encore l'assurer pour } \\
\text { certain. Quiconque ne croit pas } \\
\text { qu'il en est vraiment ainsi, s'il } \\
\text { lui arrive un jour de monter lui- } \\
\text { même jusque-là, s'apercevra que } \\
\text { je dis la vérité." }\end{array}$ & $\begin{array}{l}\text { (...) } \\
\text { Je vis deux merveilles dans } \\
\text { le palais du roi ; un puits qui } \\
\text { n'était pas fort profond, où en } \\
\text { descendant on entendait tout ce } \\
\text { qui se disait dans le monde; et un } \\
\text { miroir au-dessus, où en regardant } \\
\text { on voyait tout ce qui s'y passait.J'y } \\
\text { ai vu souvent mes amis et ceux de } \\
\text { ma connaissance, mais je ne sais } \\
\text { s'ils me voyaient. Si quelqu'un ne } \\
\text { veut pas me croire, quand ily aura } \\
\text { été, il me croira. }\end{array}$ \\
\hline
\end{tabular}

Tabela 1: tradução de Nicolas Perrot d'Ablancourt
9 Histoire de la télévision. Disponível em <http://histv2. free.fr/litterature/lucien.htm>. Acesso em 11/jan/2012.

10 Histoire de la télévision. Disponível em <http://histv2. free.fr/litterature/lucien.htm>. Acesso em 11/jan/2012. 


\begin{tabular}{|c|c|}
\hline $\begin{array}{l}\text { ARISTOPHANE. Les Guêpes. } \\
\text { Trad. Hilaire Van Daele. Paris: } \\
\text { Société d'édition Les Belles } \\
\text { Lettres, 2002, p. 09-10. }\end{array}$ & $\begin{array}{l}\text { RACINE, Jean. Les Plaideurs: } \\
\text { édition présentée, établie et } \\
\text { annotée par Georges Forestier. } \\
\text { Paris : Éditions Gallimard, } 1999 \\
\text { et } 2006 \text {. }\end{array}$ \\
\hline $\begin{array}{l}\text { Le second serviteur (se tournant } \\
\text { vers le public) }\end{array}$ & $\begin{array}{l}\text { ACTE premier,Scène I, Petit Jean } \\
\text { Petit Jean, traînant un gros sac de } \\
\text { procès. }\end{array}$ \\
\hline $\begin{array}{l}\text { (...) } \\
\text { Nous avons un maître, celui-là } \\
\text { qui dort là-haut, le grand qui est } \\
\text { sur le toit. Il nous a chargés tous } \\
\text { les deux de garder son père qu'il } \\
\text { a enfermé, pour l'empêcher de } \\
\text { sortir. Car ce père est atteint d'une } \\
\text { maladie étrange, que personne } \\
\text { au monde n'imaginerait, s'il ne } \\
\text { l'apprenait de nous. À preuve, } \\
\text { devinez. (...) }\end{array}$ & $\begin{array}{l}\text { Ma foi ! sur l'avenir bien fou qui } \\
\text { se fira: } \\
\text { Tel qui rit vendredi, dimanche } \\
\text { pleurera. } \\
\text { Un juge, l'an passé, me prit à son } \\
\text { service; } \\
\text { Il m'avait fait venir d'Amiens } \\
\text { pour être Suisse. } \\
\text { (...) }\end{array}$ \\
\hline $\begin{array}{l}\text { Je vais dire à présent la maladie } \\
\text { du maître. Il a l'amour de l'Héliée, } \\
\text { comme personne. Sa passion, } \\
\text { c'est cela, être juge, et il geint s'il } \\
\text { ne siège au premier rang. }\end{array}$ & $\begin{array}{l}\text { C'est dommage : il avait le cœur } \\
\text { trop au métier; } \\
\text { Tous les jours le premier aux } \\
\text { plaids, et le dernier, }\end{array}$ \\
\hline $\begin{array}{l}\text { Quant au sommeil, il n'en voit } \\
\text { pas un atome de la nuit; ou, s'il } \\
\text { ferme les yeux, ne fût-ce qu'un } \\
\text { instant, c'est là-bas que son esprit } \\
\text { voltige pendant la nuit, autour de } \\
\text { la clepsydre. }\end{array}$ & $\begin{array}{l}\text { Et bien souvent tout seul ; si l'on } \\
\text { l'eût voulu croire } \\
\text { Il y serait couché sans manger et } \\
\text { sans boire. } \\
\text { Je lui disais parfois : Monsieur } \\
\text { Perrin Dandin, } \\
\text { Tout franc, vous vous levez tous } \\
\text { les jours trop matin. } \\
(\ldots)\end{array}$ \\
\hline
\end{tabular}




\begin{tabular}{|l|l|}
$\begin{array}{l}\text { L'habitude qu'il a de tenir le } \\
\text { suffrage fait qu'il se lève en } \\
\text { serrant les trois doigts, comme s'il } \\
\text { mettait de l'encens sur l'autel à la } \\
\text { nouvelle lune. } \\
\text { (...) }\end{array}$ & $\begin{array}{l}\text { Il nous veut tous juger les uns } \\
\text { Il marmotte toujours certaines } \\
\text { patenôtres } \\
\text { Où je ne comprends rien. Il veut, } \\
\text { bon gré, mal gré, } \\
\text { Ne se coucher qu'en robe et qu'en } \\
\text { bonnet carré. }\end{array}$ \\
\hline $\begin{array}{l}\text { Comme son coq chantait dès la } \\
\text { nuit close, il prétendit que pour } \\
\text { l'éveiller tard il avait été séduit } \\
\text { par les prévenus et en avait reçu } \\
\text { de l'argent. }\end{array}$ & $\begin{array}{l}\text { Il fit couper la tête à son coq, de } \\
\text { colère, } \\
\text { Pour l'avoir éveillé plus tard qu'à } \\
\text { l'ordinaire; } \\
\text { Il disait qu'un plaideur dont } \\
\text { l'affaire allait mal } \\
\text { Avait graissé la patte à ce pauvre } \\
\text { animal. } \\
\text { Depuis ce bel arrêt, le pauvre } \\
\text { homme a beau faire, }\end{array}$ \\
\hline $\begin{array}{l}\text { Aussi le gardons-nous sous les } \\
\text { verrous, pour l'empêcher de } \\
\text { sortir. Car son fils est désolé de } \\
\text { sa maladie. }\end{array}$ & $\begin{array}{l}\text { Son fils ne souffre plus qu'on lui } \\
\text { parle d'affaire. } \\
\text { Il nous le fait garder jour et nuit, } \\
\text { et de près : } \\
\text { Autrement, serviteur, et mon } \\
\text { homme est aux plaids. } \\
\text { Pour s'échapper de nous, Dieu } \\
\text { sait s'il est allègre. }\end{array}$ \\
&
\end{tabular}

Tabela 2 : Les Guêpes de Aristófanes e Les Plaideurs de Racine

$\mathrm{Na}$ tabela 1, encontram-se dois trechos traduzidos a partir do mesmo texto de partida em latim, Histoire véritable de Lucien de Samosate, o qual não está reproduzido no quadro. $O$ trecho da coluna da esquerda é uma tradução de Pierre Grimal de 1958. O trecho da coluna da direita é uma tradução de Nicolas Perrot d'Ablancourt de 1664, período em que as traduções eram conhecidas como Les Belles Infidèles. Pode-se perceber a leveza e a busca pela beleza na linguagem da tradução de d'Ablancourt. Há trechos suprimidos, há rimas (tout ce qui se disait, tout ce qui s'y passait) poucas repetições de palavras (o que não acontece no trecho de Grimal que se aproxima de uma tradução "palavra por palavra"). Pode-se concluir que na tradução de Grimal o foco é o texto de partida. A linguagem de d'Ablancourt é nitidamente mais sucinta e bem organizada, resultado 
de uma busca pela beleza estilística da forma, ou seja, na tradução de d'Ablancourt o foco é o texto de chegada.

$\mathrm{Na}$ tabela 2, reproduzem-se, na coluna da esquerda, trechos traduzidos do grego para o francês do texto de partida ${ }^{11}$ Les Guêpes de Aristófanes pela tradutora Hilaire Van Daele de 2002. Na coluna da direita, os trechos correspondentes da peça Les Plaideurs de Racine, cuja fonte declarada é a peça grega. A amostragem pode indicar trechos muito semelhantes em relação ao conteúdo (os protagonistas de ambas as peças são viciados em julgar, razão pela qual não conseguem dormir, a apresentação do enredo se dá por meio de um serviçal que fala ao público, alguns episódios secundários trazidos ao público são semelhantes como a questão do galo que foi seduzido por um inimigo e por essa razão não cantou no horário certo; contudo, há também inúmeras adequações visíveis tanto em relação à linguagem quanto aos detalhes do enredo (equivalência de efeitos). Racine escreve Les Plaideurs em versos alexandrinos, medida métrica diferente da utilizada no texto-fonte e compõe as estrofes segundo um determinado padrão de rimas (AABB).

As amostragens indicam que as práticas são diferentes (declaradamente uma é tradução (tabela 1) e a outra é inspiração (tabela 2), mas os métodos utilizados são iguais, bem como a filiação nos textos clássicos está presente em ambos. E essa afirmação só é possível uma vez que se pode encontrar trechos no texto-fonte de Les Guêpes, na tabela 2, muito parecidos e até iguais ao texto de chegada Les Plaideurs. Poder-se-ia chamar de "tradução" segundo os parâmetros seguidos no período das Les Belles Infidèles à adaptação feita por Racine. Da mesma forma, as alterações do texto de chegada de d'Ablancourt, na tabela 1, possibilitam dizer tratarse de uma adaptação ou recriação a partir de um orginal, e não uma prática tradutória.

\section{Conclusão}

Alvo de muitos questionamentos e preconceitos até hoje por parte dos estudiosos da área de tradução, o período conhecido como Les Belles Infidèles na França do século XVII é fundamental para entender toda a literatura clássica da chamada "Época de Ouro da Literatura Francesa". Se cada país, se cada povo, ao longo da história construiu sua língua e literatura levando em consideração as suas questões internas e práticas culturais, as quais são específicas de cada grupo, seria um erro estudar-se as práticas tradutórias das Belles Infidèles sem um questionamento sobre as razões pelas quais elas se estabeleceram. Outra questão relevante é a utilização do termo "tradução" para a prática tradutória desse período com
${ }^{11}$ Seria impossível para a autora deste artigo trabalhar com a língua grega por desconhecê-la. 
redobrada atenção, contextualizando-o em seu período histórico e segundo suas finalidades específicas. As questões aqui colocadas sobre fidelidade estilística dinâmica e equivalência de efeitos possiblitam a atualização do termo "tradução", no século XXI, em relação à prática exercida no século XVII francês, para "adaptação" ou até mesmo "recriação segundo o modelo dos antigos".

Se a prática de uma tradução que corrompe o texto de partida, como é visto o período chamado Les Belles Infidèles, é alvo de críticas pelos estudiosos da tradução, tal postura não se dá caso seja analisada sob o prisma da construção de uma língua e literatura nacionais específicas e até hoje muito estimadas e estudadas. Admiram-se as obras magníficas de Racine e Molière, por exemplo, mas não se visualiza que a tradução, segundo os parâmetros do século XVII na França, foi uma das fontes mais produtivas para a construção de uma literatura até hoje admirada. Observado sob esse prisma, o estudo do período aqui analisado pode ser observado com muito mais profundidade e ganho ao pesquisar da área de literatura, língua e até mesmo da tradução.

ARISTOPHANE. Les Guêpes. Trad. Hilaire Van Daele. Paris: Société d'édition Les Belles Lettres, 2002.

DOLET, E. "La manière de bien traduire d'une langue en autre". In: BORGES DE FAVERI, C.; TORRES, Marie-Helène Catherine (Org.). "A maneira de bem traduzir de uma língua para outra". Clássicos da Teoria da Tradução - Antologia bilíngue/francês-português, 2004. Volume II.

BALLIU, C. "Los traductores transparentes: historia de la traducción en Francia durante el período clásico". In. Revista Hyeronymus Complutensis, Madrid: Centro Virtual Cervantes, edição de 1995, n.1. Disponível em $<$ http://cvc.cervantes.es/lengua/hieronymus/pdf/01/01_009.pdf >. Acesso em: 28/out/2011.

CHOLEWKA, N. Notas sobre Nicolas Perrot d'Ablancourt. Musée Virtuel des Dictionnaires. Disponível em <http://www.u-cergy.fr/dictionnaires/ auteurs/perrot.html>. Acesso em: 20/out/2011.

D'ABLANCOURT, P. N. "Carta ao Senhor Conrart Conselheiro e Secretário do Rei”. In: FAVERI, C. B. De; TORRES, M.-H. C. (Org.). 
"Lettre à Monsieur Conrart - conseiller et sécrétaire do roi". Trad. de Teresa Dias Carneiro. Antologia bilíngue: clássicos da teoria da tradução (francês-português). 1.ed. Volume 2. Florianópolis : NUT/UFSC, 2004. p.48-59.

FURETIÈRE. Le Roman bourgeois : Chronologie, Présentation, Dossier, Bibliographie et Lexique par Marine Roy-Garibal. Paris: Flammarion, 2001.

MEDJIRA, N. El. "Fidélité en traduction ou l'éternel souci des traducteurs". Translator Journal. Volume 5, n.4, octobre 2001, disponível em <http:// translationjournal.net/journal//18fidelite.htm>. Acesso em: 11/out/2011.

RACINE, Jean. Les Plaideurs : édition présentée, établie et annotée par Georges Forestier. Paris: Éditions Gallimard, 1999 e 2006.

.Les Plaideurs : présentation et notes de Henry Gidel. Paris: Librarie Générale Française, 1997. 1999.

. Les Plaideurs : présentation de Jean-Yves Huet. Paris: Flammarion,

Les Plaideurs : notice et annotation par Jean Dumarçay. Paris: Librarie Delagrave. 1967.

SELIGMANN-SILVA, S.. "Do gênio da língua ao tradutor como gênio". DELTA: Documentação de Estudos em Lingüistica Teórica e Aplicada, vol.19, no.spe. São Paulo: 2003. Disponível em <http://www.scielo.br/scielo. php?script $=$ sci_arttext\&pid=S0102-44502003000300011 $>$. Acesso em: 20/out/2011.

ZUBER, Roger. Les «Belles Infidèles » et la formation du goût classique : Perrot d'Ablancourt et Guez de Balzac. Paris: Armand Colin, 1995. 